\title{
Has the Holy See become an NGO?
}

\section{The Vatican's disruption of the Cairo population conference last week is a sign that it should in future enjoy the status of just another pressure group in relation to international negotiations.}

THE first week of the UN population conference at Cairo will have disappointed organizers. Despite careful negotiation, over several months, of the draft statement which it had been hoped the conference would endorse this week, the proceedings have been dominated by protests led by the Vatican over references to abortion in the document. That there might be trouble had been amply signalled in advance; the Vatican's views on abortion are well-known, and deserve respect. But its demeanour last week, and its somewhat less than successful attempt to recruit moslem countries to its cause, are more reminiscent of how pressure groups attempt to break up public meetings by obduracy rather than the intervention of a responsible member of the United Nations. The question then arises whether, by behaving as if it were a pressure group, it should be dealt with by the United Nations as if it were one - as a non-governmental organization or "NGO" in the lingo of international conferences.

The reason why the Vatican's stance at Cairo is more properly described as disruptive rather than moral is constitutional. The United Nations is, by design, a gathering of diverse states. Universality of membership is more relevant to its effectiveness than homogeneity. To the relief of the world at large, the present members include China (one of the five permanent members of the Security Council), whose strict population policy relies to some degree on abortion. But the logic of the Vatican's stance last week is that it should now campaign for the expulsion of the world's most populous state from the United Nations. (China is not the only candidate for this treatment.) That, of course, is the reductio ad absurdum from which even the Vatican would shrink.

That argument is not meant to undermine respect for the substance of the Vatican's complaints, which appear (from last week's reports from Cairo) to be two: all abortion is murder, while national population policies must entail the unwarrantable interference of governments in family life. The Vatican, to its credit, has been consistent on the first point. Its position is that a human embryo is a person from the moment of its conception.

The simplicity of that doctrine is admirable, but it is not everywhere accepted. Arguments about the status of preimplantation embryos, or about the viability of embryos in the absence of a uterus, are irrelevant to the context of that statement. The fact is that, by allowing abortion to be legal under specified conditions, many governments have implicitly rejected the Vatican's position. Its redress is to persuade its adherents in the countries concerned to persuade their governments to a different view. The Vatican has not been idle in that respect.

The second of last week's complaints is potentially more substantial, which is not to allow that the draft statement prepared for last week's conference is defective in that respect. On the contrary (see Nature 370, 583-584; 1994), that document sought merely to accelerate the demographic transition expected to follow increased prosperity by reinforcing the tendencies in that direction already apparent. Education, the public health of children and the "empowerment of women" were offered as chief among the reinforcing agents. That implies a bottom-up, not a top-down, strategy. The Vatican would have been better advised to plead for a statement in the final declaration of the conference that the coercion of individuals should play no part in national population policies.

The evident difficulty, for the Vatican, is that such a more constructive position would have entailed its assent to the prevalence of contraception, and of the legality of abortion, in many of the states to which the final declaration is addressed. But the sad consequence of its spurious protest last week is that the conference will have failed to flush out the opposition to the empowerment of women amply, but silently, represented at Cairo.

What will happen next? The Vatican's intervention has diverted attention from many important issues, and particularly from questions of how rapid population growth is a cause of impoverishment in the poorest of poor states. The hope now must be that something will nevertheless be done to finance population projects that developing countries welcome as instruments of development. Meanwhile, the Vatican and the United Nations separately should consider whether the Holy See should simply be registered as an NGO, a pressure group entitled to observer status at future meetings but unlicensed to be disruptive.

\section{The last accelerator?}

If Europe cannot agree on its planned accelerator, it should internationalize the project quickly.

EUROPE seems well on the way to losing the Large Hadron Collider (LHC) planned for CERN, the cooperative highenergy physics laboratory at Geneva. Although it seemed as recently as June that the enterprise would go ahead, the 